\title{
Law of the Sea (2018)
}

\author{
Anastasia Telesetsky*
}

This practice note explores two aspects where the international law of the sea overlaps with evolving concepts of disaster. This note will highlight legal developments arising at the nexus of disaster law and law of the sea from 2018. The first portion of this note will describe "traditional" law of the sea disasters in terms of calamitous events leading to losses of vessels. These types of disasters are usually covered by private international law tools such as insurance. In the case of oil spills from tankers, these disasters may be also addressed through sovereign trust funds. The second portion of this note will focus on "nontraditional" disasters due to large-scale environmental damage. For 2018, the focus will be on overfishing and accumulation of marine plastic debris.

\section{Traditional Marine Disasters}

Shipwrecks and ship collisions have long been part of the lore and reality of maritime transport. Even though regulations adopted under the International Maritime Organization (IMO) in combination with admiralty laws have create a legal framework for reducing maritime risks that contribute to disasters, "traditional" vessel disasters continue as almost $90 \%$ of global trade in goods is transported on a marine vessel. In 2018, according to Allianz Safety and Shipping Review (based on data compiled from 2017), ${ }^{1}$ the number of collisions and accidents had decreased due in part to improvements in ship design, better navigational tools, and risk management strategies. Of 94 losses of vessels, $3^{0}$ losses were in the region of the South China Sea due to crowded seas, piracy, lax safety standards, political risks, and typhoons. An inability to respond quickly to Typhoon Damrey in 2017 led to the loss of 6 vessels in the South China Sea region. In investigating these losses based on vessels running aground on reefs and several major fires, the insurance agencies found that $75 \%$ of the US $\$ 1.6$ billion losses could be attributed to human error including mislabeling of cargo.

* Professor of Law, College of Law, University of Idaho.

1 Allianz Global Corporate \& Specialty, 'Safety and Shipping Review 2018 - An annual review of trends and developments in shipping losses and safety' available at <https://www.agcs.al lianz.com/content/dam/onemarketing/agcs/agcs/reports/AGCS-Safety-Shipping-Review -2018.pdf >, last accessed (as any subsequent URL) on 25 June 2019. 
Relying less on regulatory changes than on social changes, the shipping industry is attempting presently to understand more about the drivers of human behavior, particularly the pressure from commercial parties on maintaining schedules associated with global supply chains. The shipping industry is also investing in additional sensor technology such as hull stress monitoring systems to be used to provide warnings to captains during severe weather.

Some shipping companies are also experimenting with the possibility of autonomous shipping that may raise interesting liability questions about who is to be held responsible in the case of an accident - the company who purchases the ship, the programmer of the automation software, or some combination of actors. Current shipping liability laws only cover vessels with crews. The IMO in 2018 began an investigation into the navigational and environmental safety of autonomous vessels. ${ }^{2}$ The widespread deployment of these vessels could have implication for both short-term and long-term disaster risk management.

Some countries such as the United States addressed the sources of maritime disasters through improved legislation. In September 2018, the U.S. Congress voted in favor of the Hamm Alert Maritime Safety Act of 2018, a law to address ongoing concerns about the safety culture in cargo shipping. The law was named to honor a mariner who lost his life in one of the U.S. worst domestic shipping disaster when the El Faro, a cargo vessel crewed by 33 relatively experienced crew members, was struck by Hurricane Joaquin, the most powerful storm to strike in that area since $1800 .{ }^{3}$ The series of events that led to the loss of the El Faro was emblematic of an increasingly lax safety culture among U.S. merchant marines reflected in 21,00o vessel deficiencies being identified on U.S. commercial vessels and issuances of "no-sail" requirements for 2500 vessels. The Commandant of the Coast Guard is now required to publish on a public website information about each domestic vessels' compliance with maritime safety codes to help individual merchant mariners to understand the safety record of a given vessel before signing on to become crew. ${ }^{4}$ The Comptroller General will audit the Coast Guard's safety management programs to

2 MSC, 'Regulatory Scoping Exercise on Maritime Autonomous Surface Ships' (3-7 December 2018), available at <http://www.imo.org/en/MediaCentre/MeetingSummaries/MSC/Pages/ MSC-10oth-session.aspx $>$.

3 The El Faro incident was the worst maritime disaster for a U.S. flagged vessel since 1983. Frank Hamm was the helmsman on the 40-year old El Faro that traveled between Jacksonville, Florida and Puerto Rico when the ship went down in the Bahamas after its structural integrity was compromised with no safety plan in place to rescue the crew.

4 Save our Seas Act Public Law 115-265, Sec. 204 (2018). 
determine the effectiveness and implementations of safety management plans with a particular focus on addressing severe weather. ${ }^{5}$ The Hamm Alert Act directs the Coast Guard to triple its inspection staff and to improve its training of Coast Guard personnel on marine safety matters. ${ }^{6}$ The Coast Guard is further required to review its technical policies on essential safety features for vessels including, for example, vessel stability standards and life-saving equipment, as well as the reliability of technologies being used for search and rescue including data buoys. ${ }^{7}$ In addition to technical revisions, the Coast Guard will improve its oversight of so-called "recognized organizations" including classification societies by opening a new office with inspectors, investigators, and auditors. ${ }^{8}$ The Coast Guard is also required to launch a pilot program to create an anonymous reporting mechanism that would allow crew members to communicate urgent safety concerns directly to the Coast Guard. ${ }^{9}$ At the same time that the U.S. Congress approved the Hamm Alert Act, Congress also approved the Coast Guard Blue Technology Center of Expertise Act designed to assist the U.S. Coast Guard in improving its search and rescue mission and emergency responses.

In addition to maritime casualties, traditional maritime disasters may involve spills of oil, bulk chemicals, and other hazardous chemicals with disastrous impacts on coastal communities and ecosystems. Under the Law of the Sea, States have an obligation to notify neighboring States of potential pollution emergencies and to jointly respond to the pollution incident. ${ }^{10}$ Under national contingency plans, States agencies organize emergency responses wherever the response by a vessel to a spill is inadequate. At present, there is little harmonization across national contingency plans, raising question about how effective a bilateral or multilateral response to a major spill incident. The largest tanker spill of natural gas condensate since 1991 highlighted the geopolitical difficulties in coordinating adequate multilateral contingency planning.

In January 2018, the Sanchi, a Panamanian-flagged and Iranian-owned tanker collided with a Hong Kong registered bulk freighter and sank in high

$5 \quad$ Save our Seas Act Public Law 115-265, Sec. 205 (2018).

6 Save our Seas Act Public Law 115-265, Sec. 210 (2018).

7 Save our Seas Act Public Law 115-265, Sec. 212 paras. (a)(1) and (c) (2018).

8 Save our Seas Act Public Law 115-265, Sec. 215 (2018). Examples of "classification societies" recognized by the Coast Guard include the American Bureau of Shipping, Class NKK, Det Norske Veritas, Germanischer Lloyd, Lloyd's Register, DNV GL, Bureau Veritas, and RINA S.p.A.

9 Save our Seas Act Public Law 115-265, Sec. 217 (2018).

10 UN Convention on the Law of the Sea, 10 December 1982, arts. 198 and 199. 
seas off the coast of Shanghai. In addition to the human tragedy, the vessel was carrying 136,00o tons of natural gas condensate (a highly flammable petroleum product that is highly toxic to marine life that floats in the upper layers of the water column) that entered Japanese jurisdictional waters and washed up on the Japanese coast. Under the legal framework of the Law of the Sea, the affected States should have been communicating early in order to organize and execute a coordinated emergency response.

In practice, the response was less cooperative and coordinated than one might have expected from a significant maritime collision and a major pollution event. Commentators suggest that regional geopolitical distrust may have delayed an operationally adequate response to the transboundary maritime disasters. ${ }^{11}$ Notably, from an international law of the sea and disaster law perspective, even though a regional contingency plan exists under the Northwest Pacific Action plan, ${ }^{12}$ the regional plan was never activated in part because the spill exceeded the capacity of the plan. Liability issues around the spill are complicated. ${ }^{13}$ The damage from the spill was not covered by International Convention on Civil Liability for Oil Pollution Damage but would be covered by the Convention on Hazardous and Noxious Substances by Sea, if it ever goes into effect. ${ }^{14}$

Given that spill responses may be complex because of multiple private actors, there is often inadequate follow-up on disaster responses. In the U.S., the ongoing Taylor oil spill in the Gulf of Mexico is a good example of a lack of sufficient supervision to respond to a known small but chronic and cumulative problem. In 2004, an offshore oil platform belonging to Taylor Energy was damaged during Hurricane Ivan and began leaking. The company implemented a disaster response plan. In 2010, environmental groups, however, recognized that the Taylor Energy site was still leaking. As of 2018, the site is

11 Tom Corben, 'Iranian Oil Tanker Disaster Highlights Northeast Asia's Faultlines' The Diplomat (26 January 2018) https://thediplomat.com/2018/o1/iranian-oil-tanker-disaster -highlights-northeast-asias-faultlines/.

12 NOWPAP, 'Regional Oil and Hns Contingency Plan' (6 August 2015) available at <http:// merrac.nowpap.org>; MOU on Regional Cooperation Regarding Preparedness \& Response to Oil Spills in the Marine Environment of the Northwest Pacific Region (6 August 2015) available at $<\mathrm{http}: / /$ merrac.nowpap.org $>$.

13 Victoria Wei, 'Determining MT Sanchi's Compensation' (Chinese Business Law Journal, 29 May 2018), available at <https://www.vantageasia.com/determining-mt-sanchiscompensation/>.

14 International Convention on Civil Liability for Oil Pollution Damage, 29 November 1969, and 1992 Protocol; International Convention on Liability and Compensation for Damage in Connection with the Carriage of Hazardous and Noxious Substances by Sea, 3 May 1996. 
estimated to have leaked 153 million gallons over 14 years in spite of the existence of contingency planning and the implementation of a disaster response plan. ${ }^{15}$

Contingency planning is also required at offshore oil and gas platforms. A November 2018 spill in Newfoundland, Canada illustrates the challenges of executing contingency responses in places where ocean conditions are rough. In the case of the November spill, the crew of an offshore oil production area due to severe ocean conditions were unable to assess the extent of damage at the time that the SeaRose tanker was spilling 250,000 liters of oil and to respond adequately. If ocean storms continue to increase in intensity, this may have implications both how the offshore oil industry and the shipping industry operates in order to avoid situations where the extent of a disaster cannot be measured for some time. Of particular concern to international policy makers are maritime spills in regions such as the Arctic where it may be difficult to deploy contingency equipment.

Finally, emergency responses to an oil spill can create conditions for slow onset disasters given the lack of risk assessments associated with many responses. For example, research has indicated that at least some of the dispersants used to respond to the Deepwater Horizon incident may have had toxic impacts on certain species and ecosystem impacts on dependent species. ${ }^{16}$ This raises critical questions about what role disaster risk reduction might play in designing contingency planning for predictable emergencies such as oil or hazardous substance spills.

\section{Non-traditional Marine Disasters}

While the UN Convention on the Law of the Sea contemplated the need to harmonize navigational standards and respond to oil spills, the Convention did not recognize the extent of the crisis faced by the marine environment as a result of decades of overfishing, decades of plastic waste entering the oceans from not just vessels but also coastlines, and decades of dirty emissions. Members of the international community including intergovernmental

15 AJ Willingham, 'An Oil Spill You've Never Heard of Could Become the Biggest Environmental Disasters in the U.S.' CNN.com (24 October 2018), available at <https://www.cnn .com/2018/10/23/us/taylor-energy-oil-largest-spill-disaster-ivan-golf-of-mexico-environ ment-trnd/index.html>.

16 Lindsay Jasperse et al, 'Comparative Toxicity of Corexit $\%$ oil mixture on the Eastern Oyster' [2018] Aquatic Toxicology (finding that oysters exposed to the dispersant had the most compromised immune systems as compared to oysters just exposed to oil). Other studies have reflected similar results for deepwater corals. 
organization are now recognizing the risks inherent in operating under a "business as usual" model. While fisheries are unlikely to collapse overnight, the current trends reflect a slow onset disaster unless there are fundamental changes in resource use.

Overfishing by both commercial fishermen and community fishermen may destabilize coastal communities when communities are no longer able to meet basic subsistence or economic needs. The human disaster of overfishing in certain fisheries has manifested itself in the physical migration of fishermen and fishing families that are unable to survive off degraded ecosystems. In the 2018 State of World Fisheries and Aquaculture Report, the Food and Agriculture Organization (FAO) reported that of the approximately 91 million tons of fish captured from the wild, only approximately $60 \%$ of the fish are being fished within biological sustainable limits. ${ }^{17}$ The international community is attempting to address the destruction of critical food resources by improving coordination to end particularly illegal commercial fishing activities. Fifty-seven countries are members of the Port State Measures Agreement designed to combat illegal fishing by preventing ships involved in illegal fishing to access ports.

While illegal fishing is a large contributor to the existing problem of overfishing, other looming pressures on global fisheries system include warming waters and acidification. Even though scientists have been writing about the potential consequences of changing ocean conditions on fish stocks, there have been limited policy responses to the problem from international fisheries organizations. Of particular concern for food security are models that suggest that populations of tuna, a subsistence for many communities in Oceania, may be migrating out of the Exclusive Economic Zone (EEZ) of certain States and into the EEZ of other States due to changes in ocean temperatures. Current models of cooperation in this area are based on certain assumptions about the location of certain fishery stocks. The shift in fisheries may lead to nutritional insecurity for some coastal populations who are dependent on the ability to fish certain stocks unless agreements can be reached within regional fisheries organizations.

The existing International Convention for the Prevention of Pollution from Ships (MARPOL) and the London Convention on Dumping of Wastes at Sea already prevent plastic litter from being deliberately released from vessels. In October 2018, the IMO acknowledged that research indicated that more needed to be done to address the extent of marine litter being generated by ships. The IMO adopted an action plan that includes working with UN partners at

17 FAO, The State of World Fisheries and Aquaculture 2018 - Meeting the sustainable development goals (FAO 2018). 
the FAO and the UN Environmental Programme as well as member States to take some concrete actions including investigating the adequacy and availability of port reception facilities. ${ }^{18}$ Some of the action plan proposals for the fishing industry include potential regulatory changes including mandatory IMO registration for fishing vessels of a certain size and mandatory marking of fishing gear with IMO ship identification numbers. Some of the proposals for the shipping industry include introducing a mandatory requirement to declare loss of containers and contents of the containers.

Global shipping currently contributes about $2.2 \%$ of anthropogenic carbon dioxide emissions. If current shipping trends continue, the shipping industry will contribute double or triple those emission amounts by 2050 unless efforts are made to reduce the carbon intensity in the industry. In 2018, the IMO's Marine Environment Protection Committee concluded an initial strategy for reducing emissions..$^{19}$ The strategy is to be implemented on the basis of the principle of common-but differentiated responsibilities. In the short-term IMO is proposing for adoption the following types of candidate measures: evaluate energy efficiency of individual vessels, establish an existing fleet improvement programme, encourage the development of national action plans for reducing shipping emissions from vessels and ports, continue research into low-carbon and zero-carbon fuels, and establish an International Maritime Research Board. Mid-term proposed actions include: implementing programs for the uptake of low-carbon and no-carbon fuel, operationalize energy efficiency programs, possibly introduce market-based measures to reduce, and support the Integrated Technical Cooperation Program. Finally, in the long-term IMO might become involved in providing zero-carbon and low-carbon fuels to the shipping industry. In theory, the planning approach being taken by the IMO may yield good results in shifting the industry. Because member States have not set for themselves specific deadlines to meet certain measures, the time frame for achieving the program remains rather unknown.

18 IMO, 'Action Plan to Address Marine Plastic from Ships' (October 2018) available at <http://www.imo.org/en/MediaCentre/PressBriefings/Pages/20-marinelitteractionmecp 73.aspx $>$.

19 IMO, 'Adoption of the Initial Imo Strategy on Reduction of GHG Emissions from Ships and Existing Iмо Activity Related to Reducing GHG Emissions in the Shipping Sector' (13 April 2018) Annexes, available at <https://unfccc.int/sites/default/files/resource/250 _IMO\%20submission_Talanoa\%2oDialogue_April\%202018.pdf>. 